\title{
Value Orientation Of Jamaicans Compared To Students In The United States Of America
}

Barbara Dastoor, (Email: dastoor@sbe.nova.edu), Nova Southeastern University Edeta Roofe, Nova Southeastern University

Bahaudin Mujtaba, Nova Southeastern University

\begin{abstract}
This study investigates differences in the value orientation of Jamaican students who live and study in the US for an extended period compared to Jamaican students in Jamaica and US students to see if there is support for the theories of convergence, divergence and crossvergence given the effects of globalization on different countries. Dorfman and Howel's (1988) scale, which measures Power distance, Uncertainty avoidance, Collectivism, Masculinity and Paternalism, assessed value orientation in this study. The results reveal that there are no differences between Jamaican students in Jamaica and those in the US that suggests strength in the Jamaican culture as Jamaicans live in the US. However, there was only one significant difference between Jamaican students in the US and the US students; uncertainty avoidance was significantly higher for the former. This supports divergend or retaining one's distinctive cultural orientation despite ongoing interaction over time. There was no difference between US students, Jamaicans in US and Jamaican universities on all other dimensions. This lends support to convergence or merging of cultures.
\end{abstract}

\section{INTRODUCTION}

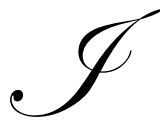

nternational expansion strategies by firms have been on the rise in the past few decades, and they present managers with new challenges on how to deal with the differences in culture. Hoffman (1998, p. 2) states, "One of the primary benefits that global expansion offers firms is the access to new markets and opportunities to utilize economies of scale." With globalization of markets, competition and organizations, individuals increasingly interact, manage, negotiate and compromise with people from different cultures (Hoecklin, 1995).

Several recent theories examine the effect of national culture on individuals' value orientation. For example, Hofstede $(1980,2001)$ identified five dimensions of cultural values: Power Distance (PD), Uncertainty Avoidance (UA), Masculinity / Femininity (Mas), Collectivism/Individuality (COLL) and Long Term-Short term Orientation (LTO) that characterize cultural differences among countries. According to Hofstede (1993), "a country's position on these dimensions allows some predictions to be made on the way their societies operate, including the management principles that are applied" (p. 89).

Other researchers developed theories to explain the extent to which one culture can affect others as people migrate and interact in the global marketplace: Convergence, Divergence and Crossvergence (CDC). Convergence (Connor, Becker \& Kakayuma, 1993) describes the merging of different cultures due to the influence of globalization and other factors that bring the cultures into close contact with one another. Divergence (Triandis, 1982) is the extent to which distinctiveness is exhibited by a specific culture despite interaction with other cultures. Finally, crossvergence (Ralston, Gustafson, Cheung \& Terpstra, 1993) is the development of a new culture with its own characteristics that result from cultures interacting with each other over time. 
Many economies are shaping their management practices to model those of the US and may, ultimately, transform their national cultures as well. According to Anderson, Glassman and Pinelli (1997), the global export of US management theories and practices through American universities in other countries assumes that other countries are eager to become Americanized, that is, to converge with the culture of the US. Other researchers, however, think that there is a general lack of success in countries adopting the so-called western management practices to develop their economy (Hofstede, 1993).

Many third world countries, including Jamaica, have adopted US management practices to achieve economic stability. Many foreign nationals work in the US and many students study there as well. The diversity of the cultures within the US presents opportunities and challenges as Jamaican students and workers are exposed to the US culture for a prolonged period of time. When they return to their home country they sometimes discover that they no longer fit into the culture, and many end up returning to the US on a permanent basis.

Immigration has become the choice of persons from many third world countries including Jamaica, as the relative prosperity in the United States becomes more attractive. People are drawn by the free way of living and independence of the courts, the social security system, developed schools and education systems, as well as the thriving gray market or shadow economy (Dougherty, 2004). Irrespective of their education, immigrants and illegal residents find employment in low-paid jobs that are unattractive for the local population. Such jobs might be in agriculture, catering and housework as well as in the building sector, mostly so-called 3-D jobs: dirty, dangerous and difficult. This is, however, better to them than the conditions in their home country

This study examines the extent to which there is divergence, convergence or crossvergence in work-related cultural values among Jamaican and US adult learners. More specifically, it focuses on differences and similarities among Jamaicans who study in Jamaica and those who study in the US and US students in the US. Hence, this research contributes to the ongoing inquiry concerning whether or not differences in cultures are disappearing due to globalization (Ricks, Toyne \& Martinez, 1990) and the extent to which cultural differences are decreasing as cultures are converging (Girlando, 1998). This paper describes the study in the following sections: Jamaican economic issues and cultural values, hypotheses and methodology, and results and conclusions.

\section{JAMAICAN ECONOMIC ISSUES AND CULTURAL VALUES}

During the 1990s, the Jamaican economy performed poorly as shown by the macroeconomic indicators. There were high levels of unemployment and negative or very low economic growth rates (Downes, 2003). The government, along with other major political leaders, agreed to the gradual liberalization of the economy and to implement a system similar to that in the US. However, problems during this period caused the Jamaican government to use economic liberalization to try to achieve low inflation, but the huge debt burden caused the exchange rate to depreciate and interest rate to continue to rise. This resulted in increased imports and decreased exports. Thus, Jamaican businesses failed to benefit from the policy of liberalization.

The education system has been a major casualty of the problems faced by Jamaica. While the primary and secondary education systems are basically successful, higher education is completed by only $4 \%$ of the population between the ages of 19 and 24 (Bloom, Mahal, King, Lee \& Castillo, 2001). Little is documented on the recent modification of the tertiary level education system in Jamaica and its similarity to that of the US. The introduction of a semester system as opposed to the yearlong program, along with the geographic proximity of both countries, led to a large number of Jamaicans studying and working in the US to supplement the shortage of skilled and professional workers that existed in the US during the late 1990s. The liberalization of the economy, the dependence of Jamaica on the US education system and the proximity of Jamaica to the US has great significance to the relationship of both countries.

Jamaica's pursuit of the policy of neoliberalism in the 1980's under Prime Minister Edward Seaga followed a period of democratic socialism that left a battered economy. This policy called for a coalition between the state and the private sector. This was successful in some sectors but the general picture of the Jamaican economy still looked grim (Henke, 1999). Liberalization, according to Bloom et al. (2001), is a move in which the state opens up a 
predominantly free economy and relinquishes control over key industries. This US style economy was adopted to encourage prosperity through a low inflation model (following the continued deterioration of the economy and the inability of the government to stabilize the economy.)

The state of the economy prompted thousands of Jamaicans to study in the US and an even greater number to seek employment there. Many US educational institutions offer business and education degree programs in Jamaica, thus exposing thousands of Jamaican students to US management policies and exposing even more Jamaicans as students in their place of work implement these management styles. A study of culture and value systems is included in management studies and so, an understanding of worldwide cultures and differences that exist in value orientations is important for Jamaicans.

There is no current consensus on the extent to which Jamaicans and Americans are the same or different in terms of cultural value orientation. Some research indicates there are no differences (Cavico \& Mujtaba, 2004) while others, for example Hofstede (2001), report there are differences. According to Cavico and Mujtaba Jamaican students tend to be very competitive and often attempt to earn the highest score within their teams and classes. This is perhaps, partly a consequence of the rigid British orientation. Cavico and Mujtaba report that Jamaicans are similar to Americans in terms of Machiavellian thinking. Machiavelli's name is often used in business and leadership literature to symbolize a sinister "real-world," "moral jungle" view. Cavico and Mujtaba's results, based on Jamaican and American students' Mach V Attitude Inventory scores, appear in Table 1. There is no difference between the two groups $(\mathrm{t}=0.0929, \mathrm{p}=0.9264)$.

Table 1: t-Test: Paired Two Sample for Means - JA Versus USA

\begin{tabular}{lll}
\hline & \multicolumn{1}{c}{ JA Score } & \multicolumn{1}{c}{ USA Score } \\
\hline Mean & 98.78947368 & 98.57894737 \\
Variance & 66.92745377 & 95.3314367 \\
Observations & 38.0 & 38.0 \\
Pearson Correlation & -00.203478569 & \\
Hypothesized Mean Difference & 0.0 & \\
Df & 37.0 & \\
T Stat & 00.092991319 & \\
P(T<=t) one-tail & 00.463206085 & \\
T Critical one-tail & 01.687094482 & \\
P(T<=t) two-tail & 00.926412171 & \\
T Critical two-tail & 02.026190487 & \\
\hline
\end{tabular}

Even though they were raised in two different cultures (countries), there are no significant differences between Jamaicans and Americans (Mujtaba \& Hinds, 2004). It appears that both the Jamaican and American cultures encourage similar attitudes with regard to management styles and strategies in the corporate environment to get ahead and secure resources for one's personal or professional objectives. A large percentage of men (approximately 54\%) were high Machs compared to only 28\% of women who scored high in this study. Therefore, Cavico and Mujtaba's research indicates that Jamaicans and Americans have similar views and attitudes toward the Machiavellian style of management (Mujtaba \& Hinds, 2004).

With respect to national culture Hofstede (1980) initially identified four cultural dimensions to explain work-related cultural differences among societies. Later Hofstede (1993) added another dimension to individualism, masculinity, power distance and uncertainty avoidance when he put forward the long-term/short-term orientation dimension. This study assesses Hofstede's four initial work-related cultural dimensions and a fifth one identified by 
Dorfman and Howell (1988). They are defined next. A later section explains why Dorfman and Howell's scale are used to assess all dimensions.

Collectivism (COLL) characterizes a culture in which people from birth onwards are integrated into strong, cohesive in-groups that, throughout their life, protect them in exchange for unquestioning loyalty (Hofstede, 2001). Collectivist cultures value group loyalty over efficiency. Individualism (IND) denotes a cultural value that stands for a society in which the ties between individuals are loose, and "everyone is expected to look after himself or herself and his or her immediate family (Hofstede, 1997, p. 51). This research follows Hofstede in viewing collectivism and individualism as end points of a single dimension. The average world score on IND is 43 and US has the highest score (99). Jamaica's lower than average score shows that the members of the society are far more concerned about the welfare of the other members of the society that those in the US culture

Femininity (sex roles) describes a society in which social gender roles overlap. Both men and women are supposed to be modest and concerned with the quality of life (Hofstede, 2001). There is no strict distinction between the work roles of men and women. Masculinity (MAS) describes a society in which gender roles are clearly distinct: Men must be assertive, tough and focused on material success; women are supposed to be modest, tender and concerned with the quality of life (Hofstede). Masculinity versus femininity differentiates countries that value economic growth and the acquisition of material goods over social and sometimes family relationships.

Paternalism (PAT) describes managers who take a personal interest in the private lives of workers (Dorfman \& Howell, 1988) and who assume the role of parents because they consider it an obligation to support and protect their subordinates (Redding, Norman \& Schlander, 1994). From an western perspective it is seen as the interference by an individual or a state in another's life another person justified by a claim that the person will be better off or protected from harm (Dworkin, 2002).

Power Distance (PD) denotes "the extent to which the less powerful members of institutions and organizations within a country expect and accept that power is distributed unequally" (Hofstede, 1997, p. 28). When PD is high, hierarchical differences are respected and organizations are highly centralized. Where it is relatively low, decentralization is popular and subordinates expect to be consulted. Hofstede calculated the world average score for $\mathrm{PD}$ as 55. The score for both the US and Jamaica (40) is lower than the world average and indicates that there is moderate equality between the various levels within the society including families and government. This, Hofstede (2003) states, makes for a more stable cultural environment.

Uncertainty Avoidance (UA) is "the extent to which members of a culture feel threatened by uncertain or unknown situations" (Hofstede 1990, p.113). Low UA describes a culture that is tolerant of ambiguity and futures unknowns. High UA fosters career stability, formal rules and long job tenure and views innovation and change as potentially dangerous. The US has a score of 46 is below the world average of 64; Jamaica's very low UA score points to a society that is open to taking risks and willing to undertake changes and innovations. This may relate to long periods of political and economic instability in Jamaica. The higher US score indicates less tolerance of risk and shows a preference for more defined set of rules and regulation governing its citizens.

Soeters and Recht (2001) posit that education prepares people for future roles in society and serves to create commitment to the implementation of societal values. The American classroom is multinational, and one role of teaching in this atmosphere is to bridge differences in values and reduce prejudices and stereotypes (Hambrick, Davidson, Snell \& Snow 1998). Although Hofstede (1993) stated that a person's basic value orientation is not easy to change, there is no evidence that after a prolonged exposure to the American culture, the value system of the Jamaican student would not be affected.

Examining the value orientation of Jamaicans and assessing their willingness to adapt to the American culture, is a way to test the divergence, convergence and crossvergence theories. Convergence speaks to the merging of different cultures by such factors as technology, globalization, economic growth and industrialization (Connor et al., 1993). Divergence, on the other hand, is a state in which there is a marked strength exhibited by individual cultures despite globalization. Crossvergence occurs as cultures are exposed to each other and some new cultural 
characteristics are formed that are distinct from any of the cultures that are interacting (Holt, Ralston \& Terpstra 1994). Researchers have put forward evidence to support all three theories.

\section{HYPOTHESES AND METHODOLOGY}

This study examines the extent to which the value orientation of Jamaican students changes after being exposed for an extended period to the culture of the US. The convenience sample includes students at a university in the southeast United States and three universities in Jamaica.

Dorfman and Howell (1988)'s cultural values scale assessed the five cultural dimensions described above. Their scales are more psychometrically sound than Hosfstede's (1980) and capture a different unit of analysis (Nicholson, Stepina, \& Hochwarter, 1990), the individual or micro level as opposed to the macro or country level. The later captures data, not on individuals, but on group, organizational and country characteristics and is appropriate when assessing national characteristics across at least three cultures. Data on citizenship was collected to identify cultural background and to sort respondents into groups for analysis.

The hypotheses are listed below by cultural orientation; the first of each set proposes that there are differences between Jamaican students in Jamaica and in the US and the second, that there are differences between Jamaican and US students in the US.

Power Distance (Hypotheses 1 and 2)

$\mathbf{H}_{1}$ : There is a difference in PD between Jamaicans who study in Jamaica and those who study in the US.

$\mathbf{H}_{2}$ : There is a difference in PD between Jamaican students who study in the US and US students who study in the US.

\section{Uncertainty Avoidance (Hypotheses 3 and 4)}

$\mathbf{H}_{3}$ : There is a difference in UA between Jamaicans who study in Jamaica and those who study in the US.

$\mathbf{H}_{4}$ : There is a difference in UA between Jamaican students who study in the US and US students who study in the US.

\section{Collectivism (Hypotheses 5 and 6 )}

$\mathbf{H}_{5}$ : There is a difference in COLL between Jamaicans who study in Jamaica and those who study in the US.

$\mathbf{H}_{6}$ : There is a difference in COLL between Jamaican students who study in the US and US students who study in the US.

\section{Masculinity (Hypotheses 7 and 8)}

$\mathbf{H}_{7}$ : There is a difference in MAS between Jamaicans who study in Jamaica and those who study in the US.

$\mathbf{H}_{\mathbf{8}}$ : There is a difference in MAS between Jamaican students who study in the US and US students who study in the US.

Paternalism (Hypotheses 9 and 10)

$\mathbf{H}_{9}$ : There is a difference in Paternalism between Jamaicans who study in Jamaica and those who study in the US.

$\mathbf{H}_{\mathbf{1 0}}$ : There is a difference in Paternalism between Jamaican students who study in the US and US students who study in the US. 


\section{RESULTS}

A total of 210 questionnaires were distributed in person and by email, 70 to each group; 160 were returned and two were eliminated due to incomplete data. The number of respondents in the final analysis was $158(\mathrm{Jam} / \mathrm{Jam}$, 70; Jam/US. 40; US/US, 48). Respondents were mostly women (65\% of the total sample) with percentages of women ranging from $54 \%$ (Jamaicans in Jamaica) to $80 \%$ (Jamaicans in the U.S.). The data indicate that $74 \%$ of the respondents in Jam/Jam were at the undergraduate level of education and $26 \%$ were at the graduate level. In the $\mathrm{Jam} / \mathrm{US}$ group $20 \%$ were undergraduate and $80 \%$, graduate students. In the US group $8 \%$ were at the undergraduate level of education while $92 \%$ were at the graduate level. Most respondents were between the ages of 22 and 30 .

The Chi Square test was used to determine if there are significant differences in the proportion of responses between the age, gender and educational categories of the three groups in the sample. There was a statistically significant difference in the proportion of men and women (gender) across the nationality groupings $\left(\mathrm{x}^{2}=8.3292>\right.$ critical value 5.991 at $0.05 \mathrm{sig}$. level). When the JAM/JAM group was compared with the JAM/US group a significant difference was found $\left(\mathrm{x}^{2}=43.77>\right.$ critical value 3.841 at $0.05 \mathrm{sig}$. level $)$. However, when the JAM/US group was compared to the US group there was no significant difference between the two $\left(x^{2}=1.6745<\right.$ critical value 3.841 at $0.05 \mathrm{sig}$. level) of the proportion of respondents in terms of gender.

There was also a significant difference in the proportion of respondents among the three groups with respect to the age categories $\left(x^{2}=47.57>\right.$ critical value 12.592 at 0.05 sig. Level, $\left.\mathrm{df}=6\right)$. When the JAM/JAM group was compared with the JAM/US group a significant difference was found $\left(\mathrm{x}^{2}=23.33>\right.$ critical value 7.815 at 0.05 sig. level). There were no respondents in the " $21 \&$ under" age groups for the Jam/US respondents, while there were $15(21 \%)$ respondents in the Jam/Jam group. In the "over 40 " age category, there were $8(12 \%)$ in the Jam/Jam group while there were 17 (43\%) in the Jam/US group. Also, when the JAM/US group was compared to the US group there was a significant difference between the two $\left(\mathrm{x}^{2}=17.34<\right.$ critical value 7.8156 at 0.05 sig. level $)$.

In the category of education there was a significant difference across the nationality grouping $\left(x^{2}=56.12<\right.$ critical value 5.991 at $0.05 \mathrm{sig}$. level). The results were similar when the JAM/JAM group was compared with the JAM/US group. There was a significant difference $\left(x^{2}=28.64>\right.$ critical value 3.841 at 0.05 sig. level $)$. However, when the JAM/US group was compared to the US group there was no significant difference between the two $\left(\mathrm{x}^{2}=\right.$ $2.48<$ critical value 3.841 at 0.05 sig. level).

Table 2 shows the mean scores for each cultural dimension for the three groups. The country score was calculated by summing the responses for items measuring each cultural dimension and calculating the mean of those scores

Table 2 - Cultural Value Orientation Mean Scores

\begin{tabular}{|c|c|c|c|c|c|c|}
\hline \multirow[t]{3}{*}{ Cultural Dimension } & \multicolumn{6}{|c|}{ Mean Scores } \\
\hline & \multicolumn{2}{|c|}{ Jam/Jam } & \multicolumn{2}{|c|}{$\mathrm{Jam} / \mathrm{US}$} & \multicolumn{2}{|c|}{ US/US } \\
\hline & Mean & Std. Dev. & Mean & Std. Dev. & Mean & Std. Dev. \\
\hline PD (Power Distance) & 1.97 & 0.26 & 2.08 & 0.49 & 2.43 & 0.47 \\
\hline UA (Uncertainty Avoidance & 4.53 & 0.08 & 4.42 & 0.09 & 4.24 & 0.07 \\
\hline COLL (Collectivism) & 3.32 & 0.44 & 3.31 & 0.42 & 3.15 & 0.35 \\
\hline MAS (Masculinity) & 3.11 & 0.51 & 1.69 & 0.71 & 1.80 & 0.50 \\
\hline PAT (Paternalism) & 3.11 & 0.27 & 0.53 & 2.88 & 0.24 & 2.43 \\
\hline
\end{tabular}

Jam/Jam respondents have the highest mean, followed by Jam/US, with US/US having the lowest mean for three dimensions: UA, COLL, and PAT. For PD the US/US respondents have the highest mean, followed by the $\mathrm{Jam} / \mathrm{US}$, with the Jam/Jam respondents having the lowest score. 
Table 3 presents the ANOVA results for PD for the three nationality/location groups. There are no significant differences in PD $(\mathrm{F}(2,12))=1.937, \mathrm{p}(.179)>.05)$. Therefore, the first two hypotheses are not supported. There is no difference in PD between Jamaicans who study in Jamaica, those who study in the US and US students in the US. Jamaicans who study in Jamaica have the lowest PD score (1.97) compared to Jamaicans who live and study in the US (2.08) and US students in the US (2.42). Low PD for Jamaicans, though not significant in this study, isconsistent with Hofstede's (1980) results.

Table 3 - ANOVA for scores on PD

\begin{tabular}{|l|ccccc|}
\hline & Sum of Squares & Df & Mean Square & F & Sig. \\
\hline Between Groups & .686 & 2 & .343 & 1.937 & .179 \\
Within Groups & 2.658 & 15 & .177 & & \\
Total & 3.344 & 17 & & & \\
\hline
\end{tabular}

The ANOVA results for UA in Table 4 show that there is a difference among the groups $(\mathrm{F}(2,12)=$ 14.153, $\mathrm{p}<.05)$. The Tukey HSD post hoc analysis in Table 5 shows there is no difference between the Jamaican students in Jamaica and those in the US. and that there is a difference between Jamaican students in the US and the US students The means in Table 2 show that Jamaicans students in the US are higher on UA (4.42) than US students (4.24).

Table 4 - ANOVA for scores on UA

\begin{tabular}{|l|c|c|c|c|c|}
\hline & Sum of Squares & Df & Mean Square & F & Sig. \\
\hline Between Groups & .197 & 2 & .099 & .153 & .001 \\
Within Groups & .084 & 12 & .007 & & \\
Total & .281 & 14 & & & \\
\hline
\end{tabular}

Table 5 - Post Hoc Tests Showing Multiple Comparisons on UA Scores

\begin{tabular}{|c|c|c|c|c|c|c|}
\hline $\begin{array}{l}\text { Group } \\
\text { (I) }\end{array}$ & $\begin{array}{l}\text { Group } \\
(\mathrm{J})\end{array}$ & $\begin{array}{l}\text { Mean Difference } \\
(\mathrm{I}-\mathrm{J})\end{array}$ & Std. Error & Sig. & \multicolumn{2}{|c|}{ 95\% Confidence Interval } \\
\hline & & & & & Lower Bound & Upper Bound \\
\hline \multirow[t]{2}{*}{1} & 2 & .1085 & .0527 & .141 & -.0322 & .2494 \\
\hline & 3 & $.2785(*)$ & .0527 & .001 & .1377 & .4193 \\
\hline \multirow[t]{2}{*}{2} & 1 & -.1086 & .0527 & .141 & -.2493 & .0322 \\
\hline & 3 & $.1700(*)$ & .0527 & .019 & .0291 & .3108 \\
\hline \multirow[t]{2}{*}{3} & 1 & $-.2786(*)$ & .0527 & .001 & -.4193 & -.1378 \\
\hline & 2 & $-.1700(*)$ & .0527 & .019 & -.3108 & -.0292 \\
\hline
\end{tabular}

* The mean difference is significant at the .05 level.

Table 6 presents the ANOVA results for COLL for the three nationality/location groups. There are no significant differences $(\mathrm{F}(2,12))=0.340, \mathrm{p}(.717)>.05)$; Hypotheses 5 and 6 are not supported. There is no difference in COLL for the three groups. 
Table 6 - ANOVA for scores on COLL

\begin{tabular}{|l|c|c|c|c|c|}
\hline & Sum of Squares & Df & Mean Square & F & Sig. \\
\hline Between Groups & .113 & 2 & .057 & .340 & .717 \\
Within Groups & 2.493 & 15 & .166 & & \\
Total & 2.606 & 17 & & & \\
\hline
\end{tabular}

Table 7 presents the ANOVA results for MAS. There are no differences $(F(2,12))=2.382, p(.135)>.05)$. Therefore, Hypotheses 7 and 8 are not supported. There are no differences in MAS for the three groups.

Table 7 - ANOVA of scores on MAS

\begin{tabular}{|l|c|c|c|c|c|}
\hline & Sum of Squares & Df & Mean Square & F & Sig. \\
\hline Between Groups & .642 & 2 & .321 & 2.382 & .135 \\
Within Groups & 1.617 & 12 & .135 & & \\
Total & 2.258 & 14 & & & \\
\hline
\end{tabular}

The ANOVA results in Table 7 show that there are no differences in PAT $(F(2,12))=1.937, \mathrm{p}(.179)>$ $.05)$; Hypotheses 9 and 10 are not supported. There are no differences in PAT for the three groups.

Table 8 - ANOVA of scores on PAT

\begin{tabular}{|c|c|c|c|c|c|}
\hline & Sum of Squares & Df & Mean Square & F & Sig. \\
\hline Between Groups & 1.712 & 2 & .856 & 2.538 & .107 \\
Within Groups & 6.070 & 18 & .337 & & \\
Total & 7.782 & 20 & & & \\
\hline
\end{tabular}

\section{CONCLUSION, IMPLICATIONS AND RECOMMENDATIONS}

This empirical study compared culture value orientation for adult learners of two nationalities (Jamaican and US) in two countries (Jamaica and US) and also Jamaican students in the US. Of particular interest was whether Jamaican students in a US university for at least two years would be different from Jamaican students in Jamaica. Results indicate that there was only one significant difference among 10 possibilities. That is, there were no differences among the three groups, except for one dimension, Uncertainty avoidance (UA). Jamaican students in the United States (US) were higher on UA than US students.

The theory of divergence (Triandis, 1982) can explain the finding that Jamaican students in Jamaica and in the US are significantly different on Uncertainty Avoidance (UA) than United States (US) students because Jamaican students in the US maintain their distinctiveness (on UA) despite their interaction with the US culture. The findings of no differences on the other four dimensions lends support to Convergence theory which proposes that different cultures become similar due to the influence of globalization and other processes that bring cultures into close contact with others.

Uncertainty avoidance (UA) is an important aspect of cross-cultural interactions in business and education. US educators should insure that Jamaican students' generally high need to avoid uncertainty and ambiguity is adequately addressed in the classroom environment. Some practical implications are that assignments should have clear and concise directions if a faculty member is to effectively excite, energize, engage, and excite Jamaican 
students. Perhaps, a comprehensive syllabus with clearly defined expectations should be provided on the first session of the class. Similarly, managers should provide comprehensive training, directions and description of what they expect of Jamaican employees in order to productively retain them since they tend to avoid uncertain conditions.

Future research could examine the theories of convergence, divergence, and crossvergence more specifically. This type of study should be extended to other cultural groups who are recent immigrants to the US. Clearly, over the last 500 years there has been convergence and crossvergence of cultures. As immigrants come to the US from a greater diversity of cultures than previously (for example, more Asian immigrants), and as globalization and the Internet continue to bring more nations together to interact in the marketplace, we may expect to see more changes.

\section{REFERENCES}

1. Bloom, D. E., Mahal, A., King, D., Henry-Lee, A. \& Castillo, P. "Globalization, liberalization and sustainable human development: Progress and challenges in Jamaica". UNCTAD/ UNDP Kingston, February 21, 2001.

2. Cavico, F. \& Mujtaba, B. (2004). "Machiavellian Values 'The Prince': Bullying, Begulling, Backstabbing, and Bargaining in the Twenty First Century Management". The Association on Employment Practices and Principles (AEPP) Proceedings. $12^{\text {th }}$ Annual International Conf. on "Leadership in the $21^{\text {st }}$ Century: Working, Living, and Surviving Organizational Life."

3. Connor, P. E., Becker, B. W., Kakuyama, Y. (1993). “A cross-national comparative study of managerial values: United States, Canada and Japan." Advances in International Comparative Studies, 8, 3-11.

4. Dorfman, P. W., Howell, J. P. (1998). "Dimensions of national culture and effective leadership patterns: Hofstede revisited". In R.N. Farmer \& E.C. McGoun (Eds.), Advances in International Comparative Management, 3, 127-150.

5. Dougherty, L. (2004). "Immigration to America. Retrieved November 23, 2004, from Northwest High School Library Media Center Web Site": http://www.kn.pacbell.com/wired/fil/pages/listimmigratli.html.

6. Downes, A (2003). "Productivity and competitiveness in the Jamaican economy". Prepared for the Inter American Development Bank, Washington DC, USA.

7. Dworkin, G. Paternalism. The Stanford Encyclopedia of Philosophy, Winter 2002 ed., Edward N. Zalta (ed.). Retrieved on November 11, 2003 from http://plato.stanford.edu/archives/win2002/entries/ paternalism/

8. Elliot, D. R. and P, Ransford, W. (1999). "What is the relationship between the government, exports, and GDP growth? The Jamaican experience explored". Studies in Comparative International Development; New Brunswick, 34(2) 40-49.

9. Elliot, D. R. \& Harvey, J. T. (2000). "Underdevelopment in Jamaica: An institutionalist's perspective" Journal of Economic Issues, 34, (2) 393-401.

10. Fernandez, D. R., Carlson, D. S. Stepina, L. P. and Nicholson, J. D (1997). "Hofstede's country classification 25 years later". The Journal of Social Psychology, 133(1), 43-54.

11. Girlando, A., P. (1998) A study of the influence of national culture on Russian students in the US.

12. Hambrick, D. C., Canney D. S., Snell, S. A. \& Snow, C, C., (1998). "When groups consist of multiple nationalities: towards a new understanding of the implications" Organizational studies, 19, 181-205

13. Henke, H. (1999). "Jamaica's decision to pursue a Neoliberal development strategy: realignment in the state-business - class triangle" Latin American Perspectives 108, (26) 7-33.

14. Hoecklin, L (1995). Managing cultural differences: strategies for competitive advantages. New York: Addison - Wesley Publishing.

15. Hoffman, J., J. (1998). "Evaluating international ethical climates: A goal-programming model" Journal of Business ethics, 17, 1861-1869.

16. Hofstede, G. (1980). Culture's Consequences: international differences in work related values. London: Sage

17. Hofstede, G. (1986). "Cultural differences in teaching and learning” International Journal of Intercultural Relations, 10 301-320. 
18. Hofstede, G. (1993). "Cultural constraints in management theories". Academy of Management Executive, 7 (1) $81-90$

19. Hofstede, G. (1997). Cultures and organization: Software of the mind. London: McGraw Hill.

20. Hofstede, G. (2001). Culture's consequences: Comparing values, behaviors, institutions across nations. London: Sage

21. Hofstede, G. (2003). Geert Hofstede "Cultural Dimensions" downloaded on September 9, 2003 from ITIM website http:// geert-hofstede.com/hofstede_united_states.shtml

22. Kelley, L., Whatley, A. \& Worthley, R. (1987). "Assessing the effects of culture on managerial attitudes: A three-culture test". Journal of International Business Studies, 18, (2) 17-31.

23. Mujtaba, B., \& Hinds, R. M. (2004). "Quality assurance through effective faculty training and development practices in distance education: The survey of Jamaican graduates". The Caribbean Area Network For Quality Assurance In Tertiary Education (Canqate). Inaugural Conference on November 3-4. Ocho Rios, Jamaica.

24. Mujtaba, B. (2004). "Comparison of learning outcomes between Jamaican students with students in the United States and the Grand Bahamas. In Delivering Superior Customer Value Course at the H. Wayne Huizenga School of Business and Entrepreneurship". Proceedings of The International College Teaching Methods \& Styles Conference. Reno, Nevada, USA. September 27-30.

25. Nicholson, J.D., Stephina, L.P., \& Hochwarter, W. (1990). "Psychological aspects of expatriate training and effectiveness". In G. Ferris \& K. Rowland (Eds.), Research in personnel and human resource management (Suppl. 2, 127-145). Greenwich, CT: JAI Press.

26. Offermann, L. R. \& Hellmann, P. S. (1997). "Culture's consequences for leadership behavior: National values in action". Journal of Cross-Cultural Psychology, 342-351.

27. Ralston, D. A., Gustafson, D. J., Cheung, F. M. \& Terpstra, R. H. (1993). "Differences in managerial values: A study of U. S., Hong Kong and PRC managers". Journal of International Business Studies, 24 (2) 249-275.

28. Ralston, D. A., Holt, D. H., Terpstra, R. H. \& Kai-Cheng, Y. (1995). "The impact of culture and ideology on managerial work values: A study of the United States, Russia and China". Academy of Managerial Proceedings, 187-191.

29. Ralston, D. A., Terpstra, R. H., Cunniff, M. K. \& Gustafson, David J. (1995). "Do expatriates change their behavior to fit a foreign culture? A study of American expatriates' strategies of upward influence". Management International Review, 35 (1) 109-122.

30. Ralston, D. A., Holt, D. H., Terpstra, R. H., \& Kai-Cheng, Y. (1997). "The impact of national culture and economic ideology on managerial work value: A study of the United States, Russia and China". Journal of International Business Studies 28, 1, 177-207.

31. Redding, S.G., Norman, A, \& Schlander, A. (1994). "The nature of individual attachment to theory: A review of East Asian variations". In H.C. Triandis, M.D. Dunnett, and L.M. Hough (Eds.), Handbook of industrial and organizational psychology, 4, 674-688. Palo Alto, CA: Consulting Psychology Press.

32. Ricks, D. A., Toyne, B. \& Martinez, Z. (1990). "Recent developments in international management research”. Journal of Management, 16, 219-252.

33. Soeters, J. L. \& Recht, R. (2001). "Convergence or divergence in the multinational classroom? Experience from the military". International Journal of intercultural relations.

34. Tan, B. (2002). "The impact of National Environment on Managerial Value Systems: a Comparative Study of Chinese Managers in the United States, Singapore and the People's Republic of China”. Management International Review, 42 (4) 473-486.

35. Taylor. S. (2003). "International Business Etiquette and manners". retrieved October 8. 2003, from International Business center Web Site: http://www.international-business-center.com/

36. Triandis, H.C. (1982). "Review of cultural consequences. International differences in work related values". Human Organization, 41, 86-90. 